\title{
Relações entre comportamentos inadequados e Habilidades Sociais em alunos dos anos iniciais
}

\section{The relationship between inappropriate behaviors and social skills in primary school \\ La relación entre comportamientos inadecuados y habilidades sociales de estudiantes em los primeros años escolares}

\author{
Jessica Cristina Piotto* \\ Jéssica Hohl de Medeiros ${ }^{* *}$ \\ Rosina Forteski Glidden ${ }^{* * *}$
}

\section{Resumo}

As Habilidades Sociais (HS) referem-se a diversas classes de comportamentos sociais de um indivíduo. O ingresso das crianças em um ambiente estruturado como a escola traz mudanças tanto para as crianças quanto para os pais, demandando maior competência social da criança. Essa pesquisa objetivou investigar o repertório de HS de alunos dos anos iniciais que emitem mais e menos comportamentos inadequados na percepção de seus professores. Participaram 64 alunos (idade média de 10,2 anos) e dez professoras dos anos iniciais de uma escola pública. Foi utilizado o Sistema Multimídia de Habilidades Sociais de Crianças (SMHSC) e gerados os testes estatísticos Qui-Quadrado, t de Student e Correlação de Pearson e medidas descritivas. Os resultados apontaram que não existiam diferenças significativas entre o escore total de HS dos alunos classificados pelas professoras como os que apresentavam mais comportamentos inadequados e o dos que apresentavam

\footnotetext{
* Psicóloga pela Fameg Uniasselvi. E-mail: jeeeh.piotto@gmail.com

** Psicóloga pela Fameg Uniasselvi. E-mail: jeh.md31@gmail.com

**** Psicóloga, Mestre em Educação pela UFPR, Docente de Psicologia na Fameg Uniasselvi.

E-mail: rsforteski@gmail.com
} 
menos comportamentos inadequados, porém, os alunos que apresentam mais comportamentos inadequados mostraram mais dificuldades para solicitar auxílio dos colegas e fazer questionamentos.

Palavras-chave: habilidades sociais; comportamento discente;percepção do professor; psicologia; educação.

\section{Abstract}

The term Social Skills (SS) refers to several social behavior categories present in an individual's repertoire. The entry of children into a structured environment such as a school brings changes for both children and parents, demanding greater social competence on part of the child. This research aimed to investigate the Social Skills repertory of students from the primary school grades of education that displayed more and less inadequate behaviors from their teachers' perspectives. Sixty-four students, with an average age of 10.2 years, and ten female teachers from the elementary grades of a public school participated in this study. The Multimedia System of Social Skills of Children (MSSSC) was used to investigate the SS. Descriptive measures and the tests: Chi-Square, Student's t and Pearson's correlation, were generated. The results showed that there were no significant differences between the total SS score of the students who presented more inadequate behaviors and those who presented fewer inadequate behaviors. However, the students who presented more inadequate behaviors also demonstrated more difficulties in requesting help from their classmates about activities, and in asking questions.

Keywords: social skills; student behavior; teacher's perception; psychology; education.

\section{Resumen}

Las Habilidades Sociales (HS) se refieren a los diversos tipos de comportamientos sociales de un individuo. El ingreso de los niños en un ambiente estructurado como lo es la escuela trae consigo cambios, tanto para los niños, como para los padres, demandando mayor competencia social del niño. La presente investigación tuvo como objetivo averiguar el repertorio de Habilidades Sociales de estudiantes de los primeros años escolares que emiten más y menos comportamientos inadecuados según la percepción de sus profesores. Participaron 64 alumnos (edad promedio de 10,2 años) y diez profesoras de una escuela pública. Fue aplicado el Sistema Multimedia de Habilidades Sociales de Niños (SMHSN); y fueron utilizados los test estadísticos Chi-cuadrado, t de Student y Correlación de Pearson, así como análisis de medidas repetidas. Los resultados mostraron que no existen diferencias significativas entre en la puntuación total de HS de los alumnos que presentan más y menos 
comportamientos inadecuados, sin embargo, los alumnos que presentaron más comportamientos inadecuados también mostraron más dificultades para pedir ayuda de colegas en las actividades y de hacer cuestionamientos.

Palabras clave: habilidades sociales; comportamiento discente; percepción del profesor; psicología; educación.

A socialização está presente nas principais etapas do desenvolvimento da criança, iniciando pela aprendizagem de habilidades motoras, da língua e daquelas relacionadas à afetividade no núcleo familiar e expandindo-se conforme também os contextos de interação são ampliados. Assim, com o ingresso em novos grupos sociais se apresentam também novos desafios relacionados à competência social. Neste sentido, a entrada na escola representa um momento único para a criança em termos de expansão das demandas de Habilidades Sociais (HS) (Do Valle \& Garnica, 2009).

O ingresso das crianças em um ambiente estruturado como a escola traz mudanças tanto para as crianças quanto para os pais. A expectativa em relação ao repertório de HS da criança aumenta a partir do momento em que ela entra em sala de aula (A. Del Prette \& Z. A. P. Del Prette, 2007). Para lidar com estas demandas, ela precisa desenvolver um repertório de HS elaborado. Em função disso, essa área está recebendo grande atenção dos profissionais da saúde e educadores. Este foco é amplamente justificável, uma vez que o estudo do tema pode contribuir tanto para a promoção da qualidade de vida, quanto para a prevenção de problemas na infância e na adolescência (A. Del Prette \& Z. A. P. Del Prette, 2009), pois as HS são consideradas um importante fator de proteção para o desenvolvimento psicossocial infantil (Grol \& Andretta, 2016).

O termo HS é definido por Caballo (1986) como um conjunto de comportamentos emitidos em contextos sociais de interação que expressam, de forma adequada a cada situação, sentimentos, desejos, opiniões ou direitos, tomando em consideração o comportamento dos demais. Tais comportamentos tendem a solucionar possíveis conflitos imediatos e minimizar a possibilidade de conflitos futuros.

Assim, as HS referem-se a diversas classes de comportamentos sociais presentes no repertório dos indivíduos. Algumas classes de HS são equivalentes para diferentes culturas e podem ser consideradas universais, 
como cumprimentar, manter e encerrar uma conversa, fazer e recusar pedidos, etc. Outras podem ser mais específicas, variando de uma maneira ampla em função da cultura, seja em sua forma, frequência ou contexto em que ocorrem. Em um mesmo grupo cultural uma atitude pode ser efetiva em uma situação e não em outra, ou pode ser adequada se emitida por determinado tipo de pessoa, como por exemplo, a criança e o adulto. Essa variedade caracteriza a especificidade situacional das HS, a sua avaliação deve sempre considerar as expectativas e padrões culturalmente estabelecidos e valorizados para diferentes contextos e situações sociodemográficas (A. Del Prette \& Z. A. P. Del Prette, 2005a).

A. Del Prette e Z. A. P. Del Prette (2005a) ressaltam que, ao contrário do que se imagina, as HS não se resumem aos comportamentos sociais entendidos como "boas maneiras". Eles referem-se a um repertório elaborado de comportamentos sociais necessários para construir relações interpessoais saudáveis e produtivas. Sua aquisição requer um processo contínuo de aprendizagem, geralmente informal, que tem início logo após o nascimento e se estende por toda a vida, tornando-se mais completo e complexo. A criança que apresenta um repertório de HS bem elaborado pode ter uma interação social mais satisfatória, pois possui boa comunicação, desenvoltura e expressividade, tornando a sua convivência cotidiana mais agradável.

As crianças e os adolescentes a cada dia deparam-se com situações que exigem aprendizagem de novos conhecimentos para responder as suas necessidades. Nos tempos atuais eles vivenciam situações complexas, nas quais são pressionados por diversos tipos de grupos, percebem regras sociais contraditórias na escola e na família, convivem com valores diferentes e defrontam-se com violência explícita diariamente nos meios de comunicação. Ao mesmo tempo em que são cobrados constantemente, também vivenciam situações nas quais podem fazer o que quiserem, deixando-os confusos (A. Del Prette \& Z. A. P. Del Prette, 2009).

No processo de seu desenvolvimento, a criança se torna mais competente socialmente à medida que compreende algumas demandas do ambiente em que vive, como normas, valores e expectativas, e que apresenta uma discriminação cada vez mais acurada destas demandas. $\mathrm{O}$ ambiente 
escolar se torna fundamental para o desenvolvimento do repertório social da criança, desde suas experiências iniciais até a pré-escola (A. Del Prette \& Z. A. P. Del Prette, 2005a).

Crianças que apresentam déficits em HS que contribuem para uma interação social satisfatória têm o seu desenvolvimento afetado. Esses déficits podem ocorrer por diversos fatores, tais como: isolamento social, relação familiar pobre, ansiedade excessiva diante de situações sociais, exposição a modelos inapropriados de comportamentos e obtenção de reforço de comportamentos passivos ou agressivos. Percebe-se assim a importância de a família, juntamente com a escola, demonstrar preocupação com as HS das crianças para que elas não venham a sofrer com dificuldades interpessoais, comportamentais e emocionais (A. Del Prette \& Z. A. P. Del Prette, 2005a).

Rodrigues e Silva (2012) destacam a relevância de treinamentos de HS que abordem, especialmente, o desenvolvimento de habilidades socioemocionais desde o início da escolarização da criança. Segundo as autoras, estes intentos têm potencial de favorecer relacionamentos interpessoais saudáveis, tanto na escola quanto em outros ambientes, o que implicaria em uma trajetória acadêmica mais adaptativa e positiva e capaz de promover resiliência. A promoção da habilidade de empatia, por exemplo, tem sido apontada como uma ação que traz bons resultados na prevenção de comportamentos agressivos e no combate à violência escolar em geral.

Apesar da existência de diversos estudos apontando a relação entre o repertório de HS, problemas de comportamento e o desempenho acadêmico das crianças, nota-se que eles não exploram todas as variáveis simultaneamente, principalmente com crianças em início de escolarização (Cia \& Barham, 2009). O estudo feito por estas autoras, do qual participaram 97 pais e mães, 99 crianças do $2^{\circ}$ e do $3^{\circ}$ anos e professoras, teve por objetivo investigar as relações entre o repertório de HS, problemas de comportamento, autoconceito e o desempenho acadêmico de crianças. Pelos resultados pôde-se verificar que o repertório de HS, o autoconceito e o desempenho acadêmico das crianças estavam positivamente correlacionados entre si, ou seja, quanto melhor o repertório de HS, melhores eram o autoconceito e o desempenho da criança. Além disso, essas três variáveis estavam negativamente correlacionadas com os problemas de 
comportamento das crianças, revelando que crianças com escores menores de HS apresentavam mais problemas de comportamento. Esses resultados mostram a relação entre o desenvolvimento socioemocional (repertório de HS, problemas de comportamento, autoconceito) e o desempenho acadêmico de crianças em fase de transição escolar e, ainda, os benefícios de programas para promover HS durante este período, com prováveis ganhos no desempenho acadêmico.

Um fator importante de ser considerado no ambiente escolar é a influência exercida pelos professores no comportamento do aluno. Para Soares, Naiff, Fonseca, Cardozo, e Baldez (2009) a perspectiva do professor em relação ao aluno pode contribuir ou não para um bom desempenho. Quando ocorre um elogio do professor para determinado comportamento discente, o aluno tende a acentuar este comportamento cada vez mais. Quando ocorre rejeição por parte do professor, o aluno tende a se afastar da situação e percebe que o professor apresenta expectativas negativas sobre ele. Britto (2013) ressalta ainda que as dificuldades apresentadas pelas crianças quanto aos relacionamentos interpessoais podem acarretar problemas de aprendizagem.

Lane, Givner, e Pierson (2004) realizaram um estudo para identificar as expectativas de 126 professores de quatro escolas da Califórnia em relação ao comportamento dos alunos. Os resultados mostraram que os professores consideraram mais importantes as habilidades das dimensões de autocontrole (controlar o temperamento na relação com os pares, responder apropriadamente à pressão dos pares, receber bem críticas, etc.) e cooperação (atender instruções, terminar as atividades de sala no tempo determinado, desenvolver as atividades acadêmicas corretamente, etc.) e menos importantes as de interação (iniciar conversação com os colegas, voluntariar-se para ajudar os colegas nas atividades de sala, juntar-se a atividades em andamento). Tais resultados, de modo geral, fazem pressupor uma predileção dos professores por habilidades de cumprimento das atividades, de seguimento de regras e de controle emocional, em detrimento daquelas que expressam mais elementos relacionados à autonomia e iniciativa do aluno.

Bandeira, Rocha, Pires, Z. A. P. Del Prette, e A. Del Prette (2006) avaliaram características da competência acadêmica e sua relação com 
o repertório de HS e com variáveis sociodemográficas de crianças. Essa pesquisa foi realizada com 257 crianças do $2^{0}$ ao $5^{\circ}$ ano do Ensino Fundamental de duas escolas públicas e uma particular, 185 pais dessas crianças e 12 professoras de uma cidade do interior de Minas Gerais. Foi encontrada correlação positiva entre o repertório de HS das crianças e sua competência acadêmica, e uma correlação negativa entre o número de reprovações das crianças e suas HS. Ou seja, crianças com melhores repertórios de HS apresentaram melhor desempenho acadêmico e um número menor de reprovações. De forma semelhante, a pesquisa de Gardinal e Marturano (2007) apontou que meninos considerados pelo professor como mais agressivos, provocativos, desrespeitosos, desobedientes, rebeldes e explosivos na relação professor-aluno apresentaram um desempenho menor em escrita e leitura.

Um estudo realizado por Molina e Z. A. P. Del Prette (2006) mostrou que existe uma relação funcional entre habilidades sociais e acadêmicas. Essa pesquisa contou com a participação de 16 alunos com dificuldades de aprendizagem. Esses alunos foram divididos em dois grupos, um grupo passou somente por intervenção acadêmica e outro por intervenção acadêmica e em HS. Concluiu-se que os alunos que participaram apenas da intervenção acadêmica obtiveram ganhos na escrita e na leitura, enquanto que os alunos que participaram da intervenção em HS e acadêmica obtiveram ganhos no repertório social e acadêmico. Assim, entende-se que para superar as dificuldades de aprendizagem é importante que o ambiente escolar apresente condições propícias para o desenvolvimento socioemocional dos alunos.

Diante do exposto, estabeleceu-se como objetivo para a presente pesquisa investigar o repertório de Habilidades Sociais de alunos dos anos iniciais que emitem mais e menos comportamentos inadequados na percepção de seus professores.

\section{MÉTODO}

Esta é uma pesquisa exploratória, descritiva e correlacional. Os procedimentos de aplicação dos questionários e do inventário foram feitos 
em ambiente escolar. Foi obtido o consentimento pelos representantes legais das crianças, por meio da assinatura no Termo de Consentimento Livre e Esclarecido (TCLE). Ainda, cada aluno foi convidado a participar da pesquisa e todos os autorizados pelos pais quiseram participar da aplicação. Os alunos foram conduzidos em grupos de dez a 12 crianças para uma sala de aula disponível para a aplicação dos instrumentos. As professoras também assinaram o TCLE. A pesquisa foi aprovada por um Comitê de Ética, com o Parecer n ${ }^{0}$ 287/2015.

\section{Instrumentos}

As professoras participantes responderam um questionário com questões sociodemográficas. Com os alunos foi utilizado o Inventário Multimídia de Habilidades Sociais para Crianças (IMHSC) (A. Del Prette \& Z. A. P. Del Prette, 2005b) e também um questionário de caracterização dos alunos. O IMHSC pode ser aplicado em crianças de sete a 12 anos e é composto por testes de autoavaliação de crianças, de avaliação das crianças por parte do professor e de avaliação do professor sobre os itens de habilidades. Nesta pesquisa foi utilizado apenas o teste de autoavaliação para crianças. O IMHSC é composto por um caderno de pranchas contendo 21 situações do cotidiano escolar de crianças dos anos iniciais do ensino fundamental e uma folha de respostas. O instrumento apresenta situações de interação da criança com seus pares e com adultos. Em cada item é solicitado à criança que indique qual a reação que ela costuma apresentar. Cada prancha contém uma situação e três alternativas de resposta, que representam 1) Comportamento Habilidoso, 2) Comportamento Não-Habilidoso Passivo e 3) Comportamento Não-Habilidoso Ativo (A. Del Prette \& Z. A. P. Del Prette, 2005b).

Os Comportamentos Habilidosos são aqueles que contribuem para a competência social e conseguem satisfazer ambas as pessoas na interação. Os Comportamentos Não-Habilidosos Passivos são aqueles que podem causar prejuízos à competência social. Referem-se a comportamentos internalizantes, ou seja, reações de esquiva, fuga, retraimento, fobia social e ansiedade diante de situações de interação social. Os Comportamentos 
Não-Habilidosos Ativos referem-se aos comportamentos externalizantes, ou seja, reações de agressividade, autoritarismo e impulsividade diante de situações de interação social. Todos os comportamentos não-habilidosos causam danos, tanto para o interlocutor quanto para o receptor (A. Del Prette \& Z. A. P. Del Prette, 2005b).

A Tabela 1 a seguir apresenta as quatro dimensões das Habilidades Sociais presentes no IMHSC - A. Del Prette e Z. A. P. Del Prette (2005b) e suas definições.

\section{Tabela 1 - Dimensões das Habilidades Sociais do IMHSC}

\begin{tabular}{ccccc}
\hline Dimensões & $\begin{array}{c}\text { Habilidade } \\
\text { de empatia e } \\
\text { civilidade }\end{array}$ & $\begin{array}{c}\text { Habilidade de } \\
\text { assertividade e } \\
\text { enfrentamento }\end{array}$ & $\begin{array}{c}\text { Habilidade de } \\
\text { autocontrole }\end{array}$ & $\begin{array}{c}\text { Habilidade de } \\
\text { participação }\end{array}$ \\
\hline Definições & $\begin{array}{c}\text { Expressão de } \\
\text { sentimentos } \\
\text { positivos de } \\
\text { solidariedade, } \\
\text { polidez social e } \\
\text { companheirismo. }\end{array}$ & $\begin{array}{c}\text { Afirmação } \\
\text { e defesa de } \\
\text { direitos e de } \\
\text { autoestima e }\end{array}$ & $\begin{array}{c}\text { Controle } \\
\text { emocional em } \\
\text { situações de } \\
\text { frustração. }\end{array}$ & $\begin{array}{c}\text { Comprometer-se } \\
\text { e envolver-se } \\
\text { com o contexto } \\
\text { social. }\end{array}$ \\
\hline
\end{tabular}

Fonte: A. Del Prette e Z. A. P. Del Prette (2005b)

\section{RESULTADOS E DISCUSSÃO}

As análises foram geradas por meio de medidas descritivas (médias, porcentagens e desvio-padrão) e dos testes estatísticos Qui Quadrado, $t$ de Student e Correlação de Pearson para relacionar variáveis e grupos, conforme objetivos de pesquisa propostos. A comparação entre grupos foi feita utilizando-se o teste $t$ de Student, dispensou-se o teste de Normalidade neste caso com base nas recomendações de Pestana e Gageiro (2003), que sustentam que em amostras maiores de 30 participantes não há necessidade de sua realização. O total de itens do Inventário de Habilidades Sociais neste trabalho alcançou um alfa de $\alpha=0,67$, recomenda-se uma consistência interna acima de 0,70 .

Para a análise comparativa entre grupos, as pesquisadoras solicitaram à secretária da escola uma lista dos alunos das turmas participantes. Nesta lista as professoras grifaram os nomes dos alunos que, na percepção delas, 
apresentavam mais comportamentos inadequados, os quais compuseram o grupo denominado Mais Comportamentos Inadequados (MACI). Para compor o grupo de alunos denominado Menos Comportamentos Inadequados (MECI) foram selecionados 12 alunos, com idade e ano letivo similares aos alunos do grupo MACI, dentre os nomes restantes na lista de participantes, ou seja, que não foram apontados pelas professoras como alunos com mais comportamentos inadequados. A seleção realizada pelas professoras foi mantida em sigilo.

\section{Participantes}

Participaram 64 alunos dos anos iniciais do Ensino Fundamental de uma escola pública de uma cidade de Santa Catarina. A média de idade dos alunos foi de 10,2 anos, com desvio padrão de 0,7. Destes, 51,6\% eram do sexo masculino e $48,4 \%$ do feminino. Em relação ao ano que estudavam, $88,8 \%$ eram do $5^{\circ}$ ano e $17,2 \%$ estudavam no $4^{\circ}$ ano. Quanto ao período, $57,8 \%$ frequentavam o matutino e $42,2 \%$ o vespertino. Dois $(n=2)$ alunos já tinham reprovado pelo menos uma vez.

A porcentagem de alunos do grupo MACI em relação ao total da amostra foi de $18,7 \%(n=12)$. Destes, onze eram do sexo masculino e um do sexo feminino. A média de idade desses alunos foi de 10,3 anos com desvio padrão de 0,7. A maioria $(n=11)$ estudava no quinto ano e um aluno no quarto ano. Metade estudava no período matutino e metade no vespertino. Quanto ao índice de reprovação, a maior parte dos alunos nunca tinha reprovado $(\mathrm{n}=11)$, apenas um reprovou uma única vez.

Participaram também dez professoras dos anos iniciais do Ensino Fundamental. A média de idade destas participantes foi de 34,3 anos com desvio padrão de 8,1. Considerando a idade das participantes categoricamente, observou-se que sete tinham entre 30 a 45 anos, duas até 29 anos e uma tinha mais de 46 anos. Em relação ao cargo que ocupavam, a maioria $(n=8)$ era professora regente, havia ainda professora de Educação Física $(n=1)$ e outro $(n=1)$.

Com o objetivo de obter uma classificação similar à feita pelas professoras, perguntou-se também aos alunos sobre sua autopercepção 
em relação a ser um bom aluno, utilizando a pergunta "Você se considera um bom aluno?". Como opções de resposta havia: "sim", "não", e "mais ou menos". Nesta questão, $54,7 \%$ responderam que se consideravam bom aluno, 43,8\% se autoavaliaram como um aluno "mais ou menos" bom e apenas um (1,6\%) não se considerou um bom aluno. Considerando apenas os resultados dos alunos classificados pela professora como com Mais Comportamentos Inadequados (MACI), observou-se que oito declararam ser "mais ou menos" um bom aluno, três declararam ser um bom aluno e um declarou não ser um bom aluno.

A classificação feita pelos próprios alunos obteve uma relação significativa ( $\left.\mathrm{c}^{2}=8,49 ; \mathrm{p}<0,05\right)$ com a classificação feita pelas professoras. Estes resultados são apresentados na Figura 1 a seguir.

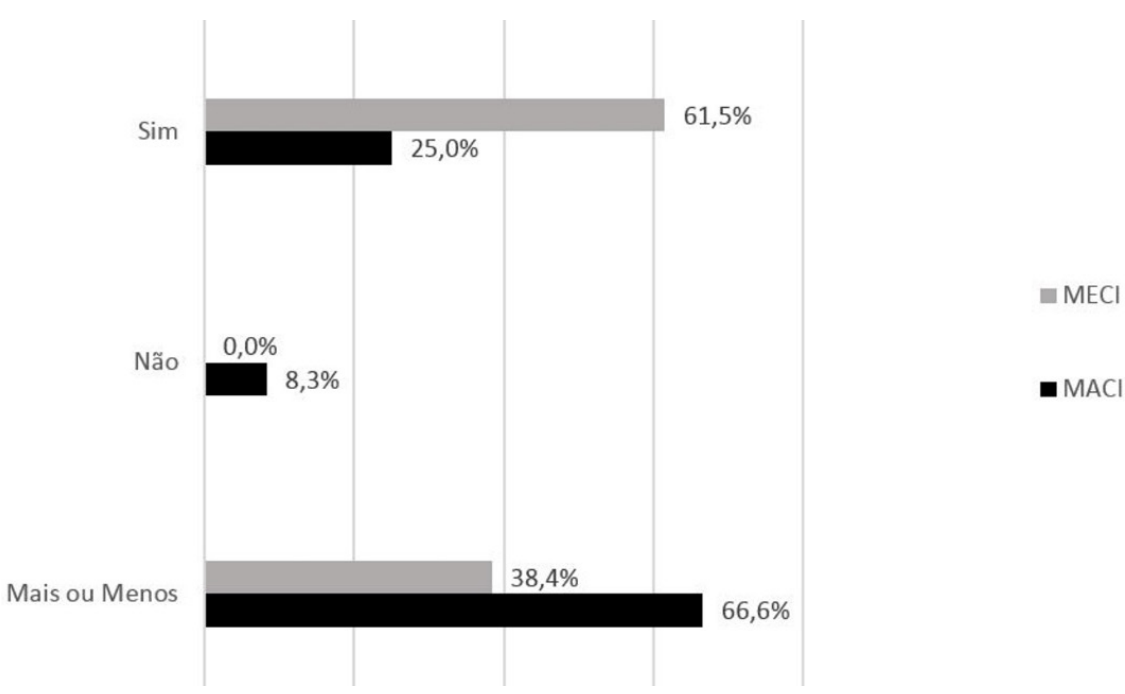

Figura 1 - Relação entre a classificação das professoras sobre os alunos com mais ( $\mathrm{MACl})$ ou menos (MECl) comportamentos inadequados e a classificação do próprio aluno $\left(c^{2}=8,49 ; p<0,05\right)$.

Conforme exposto na Figura 1, com relação à autoavaliação por parte dos alunos, pode-se perceber que, daqueles considerados pelas professoras com menos comportamentos inadequados, $61,5 \%$ se consideram bons alunos e $38,4 \%$ se consideram alunos "mais ou menos", enquanto 
dos considerados com mais comportamentos inadequados pela professora, a maioria se considerou um aluno "mais ou menos" $(66,6 \%)$ e uma porcentagem menor $(25,0 \%)$ se considerou bom aluno. $\mathrm{O}$ aluno que se autoclassificou como não sendo um bom aluno, foi também classificado pela professora como aluno com mais comportamentos inadequados.

Assim, observa-se que os alunos que, conforme classificação das professoras, emitiam menos comportamentos inadequados, também tenderam a se autoavaliarem mais como bons alunos, enquanto os alunos considerados pelas professoras com aqueles que emitiam mais comportamentos inadequados tenderam a se considerar com maior frequência como alunos "mais ou menos bons". Esse resultado aponta para uma similaridade na classificação das professoras e na autoclassificação dos alunos.

Esse resultado também sugere uma reflexão acerca da relevância da perspectiva docente sobre o comportamento do aluno, como pontuam alguns autores (Lane, Givner, \& Pierson, 2004; Soares, Naiff, Fonseca, Cardozo, \& Baldez, 2009). Alunos percebidos como menos disciplinados pelo professor tendem a apresentar desempenhos mais pobres de HS e um repertório deficiente de HS comumente culmina em emissão de comportamentos inadequados (Soares et al., 2009), o que tende a reforçar a crença do professor em relação ao aluno.Esse círculo se retroalimenta e leva à frustração do professor e à exclusão do aluno, nesta dinâmica nenhum dos atores envolvidos é favorecido.

A variável sexo dos alunos obteve relação significativa $\left(c^{2}=9,51\right.$; $p<0,05)$ com a classificação das professoras sobre os alunos que apresentavam mais comportamentos inadequados e menos comportamentos inadequados. Estes resultados são apresentados na Figura 2 a seguir. 


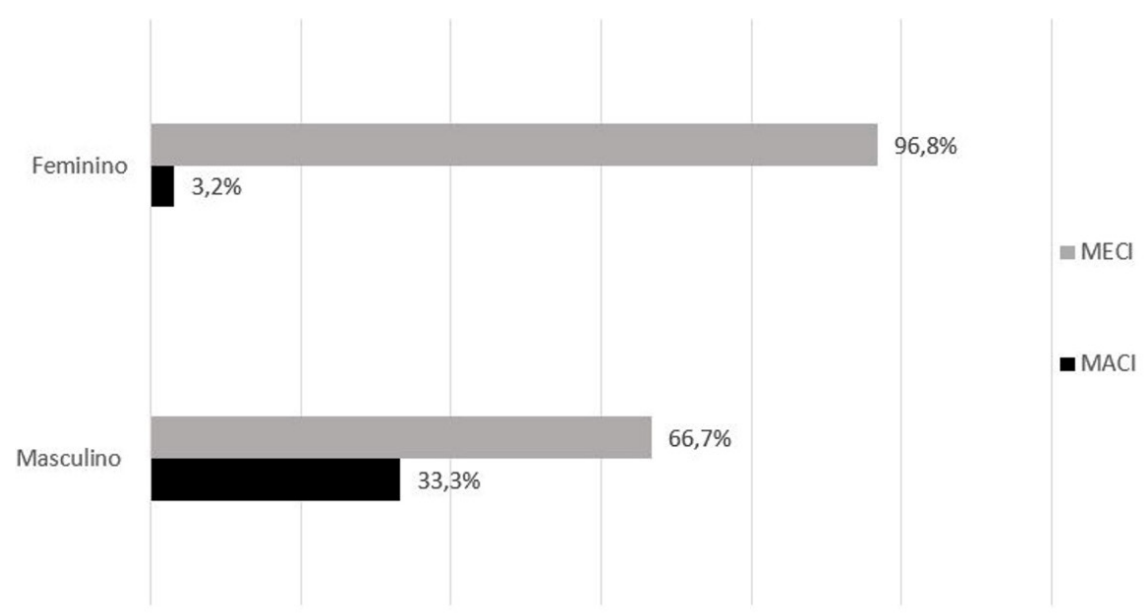

Figura 2 - Relação entre a classificação das professoras sobre os alunos com mais ( $\mathrm{MACl}$ ) ou menos (MECl) comportamentos inadequados e o sexo dos alunos $\left(c^{2}=9,51 ; p<0,05\right)$.

Conforme pode ser observado na Figura 2, das meninas, 3,2\% faziam parte do grupo MACI, enquanto dos meninos, 33,3\% foram apontados pelas professoras como pertencentes a este grupo. Portanto, verifica-se que os meninos foram classificados mais como alunos que emitiam mais comportamentos inadequados pelas professoras do que as meninas. Esse resultado remete aosda pesquisa de Joly, Dias, e Marini (2009), que revelou que os meninos apresentavam mais comportamentos agressivos do que as meninas; e da pesquisa de Dal'Igna (2007), na qual os meninos apresentaram menor desempenho escolar em relação às meninas, devido a comportamentos mais agitados, agressivos, falta de atenção, entre outros. Porém, cabe salientar aqui que os resultados da presente pesquisase originaram da percepção das professoras, já que nenhuma medida direta de desempenho ou adequação comportamental foi obtida.

A pesquisa de Gardinal e Marturano (2007) também obteve o dado de que os professores avaliaram o comportamento das meninas de forma mais positiva. No estudo de Grol e Andretta (2016) as meninas apresentaram médias mais altas de HS em relação aos meninos. As autoras concluíram 
pela necessidade de dar mais ênfase ao aprimoramento das HS dos meninos, e especialmente, de acordo com os resultados de sua pesquisa, nas habilidades de empatia-civilidade e autocontrole.

Foi constatada ainda uma relação significativa $\left(c^{2}=6,32 ; \mathrm{p}<0,05\right)$ entre a classificação das professoras sobre os comportamentos dos alunos e as pontuações do item do inventário de HS mediar conflitos entre os colegas, da dimensão Participação. Este resultado é apresentado na Figura 3.

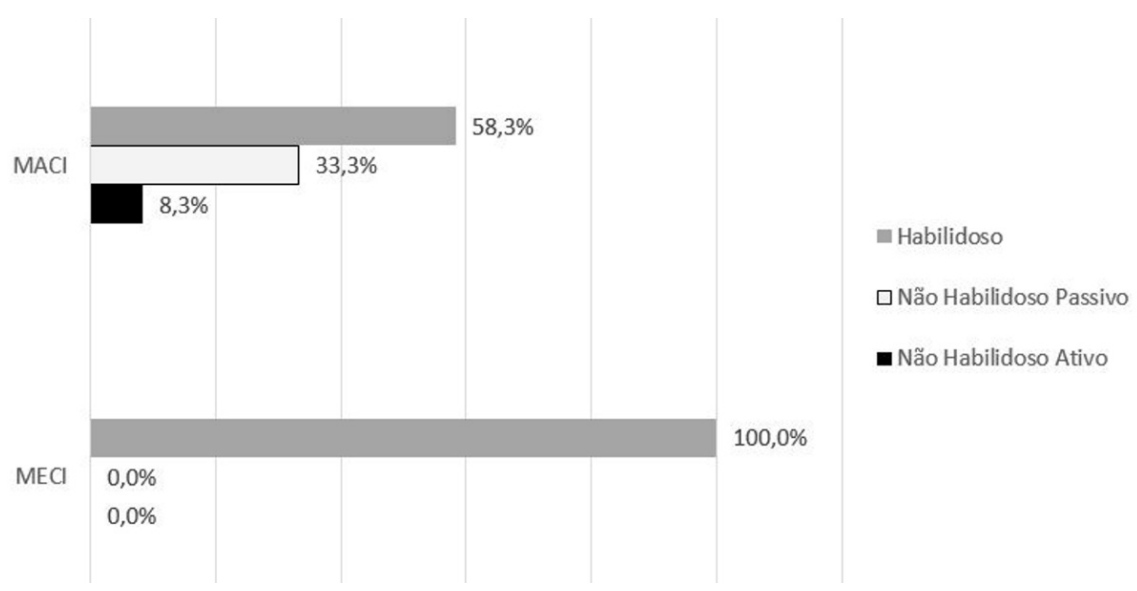

Figura 3 - Relação entre a classificação das professoras sobre os alunos com mais ( $\mathrm{MACl}$ ) ou menos ( $\mathrm{MECl}$ ) comportamentos inadequados e os resultados do item "mediar conflitos entre os colegas" $\left(c^{2}=6,32 ; p<0,05\right)$.

A Figura 3 mostra que, dentre os alunos que apresentavam mais comportamentos inadequados na opinião das professoras, 58,3\% eram habilidosos quanto ao item de mediar conflitos entre os colegas, 33,3\% eram Não-Habilidosos Passivos e 8,3\% Não Habilidosos-Ativos. Em relação aos alunos considerados com menos comportamentos inadequados, todos $(100,0 \%)$ eram habilidosos no que se refere ao item mediar conflito entre os colegas. Portanto, 41,6\% dos alunos considerados pelas professoras com mais comportamentos inadequados descreveram dificuldades no comportamento de mediar conflito entre os colegas. 
Comportamentos Não-Habilidosos Passivos, segundo A. Del Prette e Z. A. P. Del Prette (2005b) referem-se a comportamentos internalizantes, ou seja, as crianças encobrem seus sentimentos e agem de forma evitativa, fugindo ou se esquivando diante de determinadas situações. Comportamentos Não-Habilidosos Ativos referem-se a comportamentos externalizantes, ou seja, à ação agressiva, muitas vezes expressando autoritarismo e negativismo. Ambos são prejudiciais nas relações humanas.

\section{Resultados do Inventário de HS}

A Tabela 2 a seguir traz os resultados do Inventário de HS dos 12 alunos que apresentavam mais comportamentos inadequados (MACI) e dos 12 que apresentavam menos comportamentos inadequados (MECI) de acordo com a classificação das professoras.

Tabela 2 - Classificação de acordo com os escores de HS dos alunos por item

\begin{tabular}{lcccccc}
\hline \multirow{2}{*}{ Itens de Habilidade Social } & \multicolumn{2}{c}{$\mathrm{NHA}^{*}$} & \multicolumn{2}{c}{$\mathrm{NHP}^{* *}$} & \multicolumn{2}{c}{$\mathrm{HAB}^{* * *}$} \\
\cline { 2 - 7 } & $\mathrm{MACl}$ & $\mathrm{MECl}$ & $\mathrm{MACl}$ & $\mathrm{MECl}$ & $\mathrm{MACl}$ & $\mathrm{MECl}$ \\
\hline Juntar-se a um grupo de brincadeiras & 0 & 0 & 1 & 1 & 11 & 11 \\
\hline Recusar pedido de colega & 1 & 0 & 3 & 0 & 8 & 12 \\
\hline Expressar desagrado & 0 & 1 & 6 & 7 & 6 & 4 \\
\hline Pedir ajuda ao colega em classe & 0 & 0 & 3 & 0 & 9 & 12 \\
\hline Pedir mudança de comportamento & 0 & 0 & 0 & 0 & 12 & 12 \\
\hline Pedir desculpas & 0 & 0 & 0 & 0 & 12 & 12 \\
\hline Demonstrar espírito esportivo & 0 & 0 & 1 & 0 & 11 & 12 \\
\hline Mediar conflito entre colegas & 1 & 0 & 4 & 0 & 7 & 12 \\
\hline Negociar e convencer & 0 & 0 & 0 & 2 & 12 & 10 \\
\hline Oferecer ajuda & 0 & 0 & 0 & 0 & 12 & 12 \\
\hline Propor nova brincadeira & 0 & 0 & 1 & 1 & 11 & 11 \\
\hline Perguntar (questionar) & 3 & 1 & 4 & 1 & 5 & 10 \\
\hline Responder pergunta do professor & 0 & 1 & 2 & 1 & 10 & 10 \\
\hline Fazer pergunta ao professor & 0 & 0 & 1 & 0 & 11 & 12 \\
\hline Aceitar gozações & 2 & 2 & 1 & 0 & 9 & 10 \\
\hline Agradecer um elogio & 0 & 1 & 1 & 0 & 11 & 10 \\
\hline Resistir à pressão do grupo & 1 & 2 & 2 & 1 & 9 & 9 \\
\hline
\end{tabular}




\begin{tabular}{lcccccc}
\hline Consolar o colega & 0 & 0 & 1 & 0 & 11 & 12 \\
\hline Elogiar o objeto do colega & 0 & 1 & 4 & 1 & 8 & 10 \\
\hline Defender-se de acusações injustas & 0 & 1 & 1 & 1 & 11 & 10 \\
\hline Defender o colega & 0 & 1 & 2 & 0 & 10 & 11 \\
\hline
\end{tabular}

*NHA: Não-Habilidoso Ativo **NHP: Não-Habilidoso Passivo **Habilidoso

Uma análise geral e comparativa dos dados da Tabela 2 mostra que no Grupo MECI há um número maior de respostas habilidosas, em nove habilidades todos os alunos $(n=12)$ responderam assertivamente. Enquanto que todos $(\mathrm{n}=12)$ os alunos do grupo MACI responderam de forma assertiva em quatro habilidades: pedir mudança de comportamento, pedir desculpas, negociar e convencer e oferecer ajuda. Contudo, o teste $t$ não considerou significativa $(p>0,05)$ a diferença entre os dois grupos, considerando o total de escores de HS.

A inspeção dos dados da Tabela 2 permite supor que, no geral, os participantes descrevem maiores níveis de dificuldades na emissão de respostas assertivas na habilidade expressar desagrado, sugerindo padrões pouco assertivos desses alunos em defender seus direitos e preferências, pois estes alunos descreveram, em um número considerável, respostas não-habilidosas passivas.

Considerando uma análise mais específica apenas do grupo MACI, conforme a Tabela 2, observa-se também que o item do inventário de HS expressar desagrado foi o que apresentou maior número de alunos que descreveram respostas não-habilidosas passivas. Em segundo lugar estão os itens: mediar conflito entre colegas, perguntar (questionar) e elogiar o objeto do colega. Isto é, essas crianças, ao interceder quando há conflitos entre os colegas, ao questionar e ao fazer elogios aos colegas, descrevem que o fazem de maneira inadequada, por apresentarem comportamentos passivos, fugindo ou se esquivando destas situações. Os itens do inventário de HS com maior quantidade de alunos do grupo MACI que optaram pela resposta não-habilidosa ativa foi perguntar (questionar) e aceitar gozações.

Conclui-se, portanto, que algumas crianças relataram dificuldades internalizantes em relação a alguns comportamentos. Ou seja, elas descrevem não conseguir enfrentar situações referentes à expressão de 
desagrado, à mediação de conflitos entre os colegas e a realizar questionamentos de maneira adequada, optando por fugir ou se esquivar e por encobrir os seus sentimentos frente a situações que demandam estas HS. Outras crianças descreveram dificuldades externalizantes no que se refere a alguns comportamentos, relatando não lidar bem com gozações e fazer questionamentos aos colegas de forma inadequada, expressando-se de modo agressivo, negativo ou autoritário. De fato, foram descritas respostas habilidosas e não-habilidosas, tanto ativas quanto passivas, nos dois grupos, com predominância das respostas não-habilidosas passivas.

Segundo A. Del Prette e Z. A. P. Del Prette (2005b) crianças que apresentam dificuldade em relacionamentos interpessoais podem ter $\mathrm{o}$ seu desenvolvimento saudável prejudicado. Frequentemente associados a transtornos psicológicos como ansiedade e depressão, os problemas de comportamentos internalizantes influenciam no isolamento social e no autoconceito da criança. O isolamento social concomitante a estes dois transtornos com frequência denuncia um repertório pobre de HS. Por sua vez, tais déficits podem gerar desconforto e insegurança na criança quando ela se vê diante de interações sociais, especialmente em momentos em que ela precisa falar de si. No outro extremo, problemas de comportamentos externalizantes costumam estar associados a transtornos de comportamentos antissociais, agressivos ou opositores e de hiperatividade e desatenção (A. Del Prette \& Z. A. P. Del Prette, 2005b). Os problemas externalizantes têm maior prevalência em relação a outras problemáticas comportamentais e, pela associação que apresenta aos transtornos citados, têm sido importante objeto de investigação de pesquisas em Psicopatologia Infantil (Lins, Alvarenga, Paixão, Almeida, \& Costa, 2012).

\section{Habilidades sociais: análises de comparação entre grupos}

Para realização de todos os testes $t$ de comparação entre médias foi usada uma separação da amostra dos alunos em dois grupos: alunos com mais comportamentos inadequados (MACI) e alunos com menos comportamentos inadequados (MECI), ambos compostos por 12 alunos. O primeiro 
foi elencado de acordo com classificação prévia das professoras, o segundo foi separado pelas pesquisadoras, sendo composto por alunos do mesmo ano letivo e da mesma idade dos alunos do grupo MACI.

$\mathrm{O}$ teste $t$ não apresentou diferença significativa $(p>0,05)$ entre os grupos MACI e MECI, no escore total de Habilidades Sociais e também nas quatro dimensões (Habilidade de Empatia e Civilidade, Habilidade de Assertividade de Enfrentamento, Habilidade de Autocontrole e Habilidade de Participação), revelando que, estatisticamente, não há diferença entre estes dois grupos em relação às habilidades sociais descritas.

Porém, o teste $t$ apresentou diferença significativa entre os grupos nos dois itens sem fatores definidos (Não Fatores) $(t=-2,45, p=0,024)$, pedir ajuda ao colega em classe e perguntar (questionar). Neste sentido, os alunos que apresentavam mais comportamentos inadequados, segundo classificação das professoras, obtiveram uma média menor $(M=2,91$; $d p=0,99)$ do que os alunos classificados pelas professoras como os que apresentavam menos comportamentos inadequados $(\mathrm{M}=3,75 ; d p=0,62)$. Sendo assim, aqueles que foram classificados pelas professoras como alunos com mais comportamentos inadequados descreveram apresentar mais dificuldades para solicitar auxílio dos colegas nas atividades e também para fazer questionamentos.

$O$ teste $t$ não apresentou diferença significativa $(p>0,05)$ entre a variável sexo e o escore total de HS e também com as quatro dimensões do inventário. Ou seja, nesta pesquisa a variável sexo não apareceu como relevante nas HS referidas pelos alunos, quando considerados os valores totais do inventário e suas dimensões.

Nos resultados da pesquisa de Joly et al. (2009), foi observada diferença em alguns comportamentos relacionados às HS entre os sexos, na qual os meninos apresentavam mais condutas agressivas do que as meninas. O mesmo foi encontrado no estudo de Dal'Igna (2007) que explicitou que os meninos eram mais agressivos, agitados, desatentos e também apresentavam menor desempenho escolar em relação às meninas.

A pesquisa de Bandeira et al. (2006) evidenciou que as meninas apresentaram maiores escores de HS que os meninos, da mesma forma que a pesquisa de Grol e Andretta (2016). Na pesquisa dessas autoras as 
meninas, além de obterem pontuações mais altas no escore geral de HS, também atingiram médias mais elevadas nas subescalas de empatia e civilidade e de autocontrole. Assim, de modo geral, a literatura aponta para melhores desempenhos de HS no sexo feminino, discordando dos dados da presente pesquisa.

Contudo, o teste $t$ indicou diferença significativa entre os dois itens da dimensão não fatores e o sexo dos alunos $(t=2,56, p=0,018)$. Sendo assim, as alunas obtiveram média maior $(\mathrm{M}=3,88 ; d p=0,33)$ que os alunos $(\mathrm{M}=3,00 ; d p=1,00)$ no total destes itens. Este resultado mostra que as meninas são mais habilidosas em requerer auxílio dos colegas e fazer questionamentos do que os meninos.

\section{Habilidades sociais: análises correlativas entre variáveis}

Para comparação entre diversas variáveis desta pesquisa foi utilizado o teste de Correlação de Pearson. Este teste não apontou correlação significativa $(p>0,05)$ entre o escore total do inventário com as variáveis idade das crianças e ano em que estudam, divergindo dos resultados de Grol e Andretta (2016), que indicaram uma evolução das HS das crianças conforme avançavam os anos. Ou seja, crianças mais velhas apresentavam melhores níveis de HS. De outro lado, a pesquisa de Bandeira et al. (2006), apontou que quanto mais nova é a criança, melhores são as suas habilidades sociais.

Porém, o escore total da dimensão Participação do inventário de HS obteve correlação significativa negativa $(\mathrm{r}=-0,274 ; p=0,030)$ com a variável idade da criança, ou seja, quanto maior o escore nesta dimensão, menor a idade da criança. Assim, crianças mais novas descrevem ser mais habilidosas em comportamentos como mediar conflitos entre colegas, se envolver em brincadeiras e responder a perguntas da professora.

A autoclassificação da criança sobre se considerar um bom aluno apresentou correlação significativa negativa $(\mathrm{r}=-0,282 ; p=0,025) \mathrm{com}$ a variável idade. Isto significa que quanto maior a idade, menos a criança se considera um bom aluno. Pontua-se aqui o fato de que a complexidade dos conteúdos e os critérios avaliativos também vão se intensificando conforme 
a criança avança nos anos do ensino formal e que, como apontam A. Del Prette e Z. A. P. Del Prette (2009), conforme a criança cresce a demanda por novos conhecimentos aumenta.

Houve ainda uma correlação positiva significativa $(\mathrm{r}=0,393 ; p=0,001)$ entre a autoclassificação da criança sobre ser um bom aluno e a dimensão Participação, o que significa que quanto mais a criança se considera um bom aluno, mais habilidosa ela é para envolver-se em contextos sociais. Os resultados da pesquisa de Cia e Barham (2009) apresentaram correlações positivas entre o repertório de HS, autoconceito e desempenho acadêmico das crianças, isto é, quanto melhor o repertório de HS, melhor era também o seu autoconceito e o seu desempenho, resultados que se aproximam ao desta pesquisa.

O item do inventário de HS juntar-se a um grupo de brincadeiras apresentou correlação significativa positiva $(\mathrm{r}=0,350 ; p=0,005)$ com a autoavaliação dos alunos sobre ser um bom aluno. Isto significa que quanto mais os alunos tinham habilidade de ingressar em brincadeiras com um grupo, mais eles se autoavaliavam como bons alunos. O comportamento de interação refere-se à dimensão Participação. Estes resultados podem ser relacionados com a pesquisa de Menandro e Souza (2010) que traz como critério de classificação de um bom aluno, dentre outros fatores, a emissão de comportamentos como de participação e boa interação com os colegas.

Obteve-se também uma correlação negativa significativa $(\mathrm{r}=-0,368$; $p=0,003$ ) entre a autoavaliação dos alunos sobre ser bom aluno e o item do inventário de HS expressar desagrado, que se refere à dimensão Assertividade de Enfrentamento, ou seja, quanto mais os alunos se autoavaliavam como bons alunos, menor era a sua habilidade de expressão frente a alguma situação que pudesse lhe causar insatisfação. Sugere-se uma relação com os resultados da pesquisa de Menandro e Souza (2010), que mostrou que o bom aluno é considerado submisso, pois em nenhum momento ele foi citado como independente, criativo e autônomo.

O item mediar conflitos entre colegas, da dimensão Participação, apresentou correlação positiva significativa $(\mathrm{r}=0,324 ; p=0,008)$ com a 
autoclassificação dos alunos sobre ser um bom aluno. Este resultado mostra que quanto mais os alunos se consideravam habilidosos para ajudar seus colegas em situações de conflitos, mais eles se consideravam bons alunos.

A idade da criança apresentou uma correlação positiva significativa ( $\mathrm{r}=0,288 ; p=0,022)$ com o item do inventário de HS recusar pedido do colega,que se refere a dimensão Autocontrole. Isto mostra que quanto maior a idade do aluno, mais habilidoso ele era na emissão do comportamento de negar algo que o colega solicitou quando fosse contra a sua vontade.

O item do inventário de HS pedir desculpas, referente à dimensão Empatia e Civilidade, apresentou correlação negativa significativa $(\mathrm{r}=-0,256 ; p=0,043)$ com a idade da criança. Isto quer dizer que quanto mais velha era a criança, menos habilidosa ela era em relação ao comportamento de se desculpar com colegas e professores.

O inventário de HS apresenta o item mediar conflitos entre colegas que se refere à dimensão Participação. Este item obteve uma correlação negativa significativa $(\mathrm{r}=-0,424 ; p=0,001)$ com a idade do aluno. Este resultado aponta que, quanto mais a criança relatava apresentar habilidades para o comportamento de contribuir para a resolução de conflitos entre seus colegas, menor era a sua idade.

A quantidade de irmãos que os alunos possuíam obteve correlação negativa significativa $(\mathrm{r}=-0,384 ; p=0,004)$ com o item do inventário de HS oferecer ajuda, referente à dimensão Empatia e Civilidade. Isto significa que quanto maior era a quantidade de irmãos dos alunos, menor era a sua habilidade de proporcionar auxílio aos colegas.

$\mathrm{O}$ item consolar os colegas, que se refere à dimensão Empatia $e$ Civilidade, apresentou correlação negativa significativa ( $\mathrm{r}=-0,462 ; p=0,001)$ com a quantidade de irmãos dos participantes. Isto quer dizer que quanto maior era a habilidade de confortar os seus colegas, menor era a quantidade de irmãos que a criança tinha. Os dois últimos resultados denotam o relato de comportamentos mais solidários e de apoio de crianças que tinham menos irmãos. Sugere-se que um número elevado de irmãos pode contribuir para relações mais conflituosas e, assim, menos empáticas. Porém estas questões demandam investigações próprias. 


\section{CONSIDERAÇÕES FINAIS}

Este trabalho teve como objetivo investigar o repertório de Habilidades Sociais de alunos dos anos iniciais que emitem mais e menos comportamentos inadequados na percepção de seus professores. Os resultados não mostraram diferenças significativas no escore total de HS dos 12 alunos classificados pelas professoras como os que apresentam mais comportamentos inadequados e os 12 que apresentam menos comportamentos inadequados. Porém, verificou-se que aqueles que foram classificados pelas professoras como alunos com mais comportamentos inadequados descreveram mais dificuldades nas habilidades de solicitar auxílio dos colegas e de fazer questionamentos. Ainda, a maioria dos alunos classificados pelas professoras como os que emitiam mais comportamentos inadequados se considerava como "mais ou menos bons" alunos.

Desta forma, não foi possível concluir neste estudo que os alunos que emitiam mais comportamentos inadequados tinham de fato maiores déficits de HS, embora sua autopercepção sobre sua competência como aluno tenha se aproximado da percepção das professoras. Sugere-se ser importante investigar, em estudos futuros e com amostras maiores, a relação destes itens específicos com outras variáveis, de modo a aprofundar a discussão sobre os déficits apontados nesta pesquisa.

Por fim, mais alunos foram apontados pela professora para compor o grupo MACI do que alunas. Esse resultado concorda com a literatura que aponta expectativas mais positivas dos professores em relação ao comportamento das meninas. Porém, não houve diferença significativa entre os sexos com relação à qualidade do repertório de HS descrito. Este resultado, por sua vez, vai de encontro aos providos pela literatura que também explicitam maiores níveis de HS nas meninas.

Cumpre pontuar que neste trabalho não foi utilizada nenhuma medida direta, como dados de observação, para determinar a presença das habilidades sociais investigadas no repertório dos alunos. Deve-se levar em conta os limites de estudos que coletam dados apenas por meio do relato verbal, o qual pode sofrer influências de inúmeras variáveis ausentes na 
ocasião em que o comportamento relatado foi emitido. Entende-se, assim, que as conclusões neste sentido precisam ser lidas com parcimônia e sugerem-se novos estudos que ampliem os instrumentos de coleta de dados.

\section{REFERÊNCIAS}

Bandeira, M., Rocha, S. S., Pires, L. G., Del Prette, Z. A. P., \& Del Prette, A. (2006). Competência acadêmica de crianças do Ensino Fundamental: características sociodemográficas e relação com Habilidades Sociais. Interação em Psicologia, 1o(1), 53-62. doi: 10.5380/psi.v10i1.5773

Britto, A. C. de O. (2013). Indisciplina na sala de aula: contribuições da análise do comportamento (Trabalho de Conclusão de Curso). Centro Universitário Católico Salesiano Auxilium, Lins, São Paulo.

Caballo, V. E. (1986). Evaluación de las habilidades sociales. In R. F. Ballesteros, \& J. A. I. Carrobles (Orgs). Evaluación conductual: metodologia y aplicaciones (pp. 553-595). Madrid, Espanha: Piramide.

Cia, F., \& Barham, E. J. (2009). Repertório de Habilidades Sociais, problemas de comportamento, autoconceito, e desempenho acadêmico de crianças no início da escolarização. Estudos de Psicologia, 26(1), 45-55. doi: 10.1590/So103-166X2009000100005

Dal'Igna, M. C. (2007). Desempenho escolar de meninos e meninas: há diferença? Educação em Revista, (46), 241-267. doi: 10.1590/ S0102-46982007000200010

Del Prette, A., \& Del Prette, Z. A. P. (2005a). Psicologia das habilidades sociais na infância: Teoria e Prática. Petrópolis, RJ: Vozes.

Del Prette, A., \& Del Prette, Z. A. P. (2005b). Sistema Multimídia de Habilidades Sociais de Crianças. São Paulo, SP: Casa do psicólogo.

Del Prette, A., \& Del Prette, Z. A. P. (2007). Habilidades sociais, desenvolvimento e aprendizagem (2a. ed.). Campinas, SP: Alínea.

Del Prette, A., \& Del Prette, Z. A. P. (2009). Psicologia das habilidades sociais na infância: teoria e prática (4a. ed.). Petrópolis, RJ: Vozes. 
Do Valle, T. G. M., \& Garnica, K. R. H. (2009). Avaliação e treinamento de habilidades sociais de crianças em idade pré-escolar. In T. G. M. Do Valle (Org.), Aprendizagem e desenvolvimento humano: avaliações e intervenções (pp. 49-75). São Paulo, SP: Cultura Acadêmica.

Gardinal, E. C., \& Marturano, E. M. (2007). Meninos e meninas na educação infantil: associação entre comportamento e desempenho. Psicologia em Estudo, 12(3) 541-551. doi: 10.1590/S1413-73722007000300011

Grol, L. S. V., \& Andretta, I. (2016). Habilidades sociais e variáveis sociodemográficas em crianças com idade escolar: um estudo descritivo. Temas em Psicologia, 24(3), 1129-1138. doi: 10.9788/ TP2016.3-17

Joly, M. C. R. A., Dias, A. S., \& Marini, J. A. da S. (2009). Avaliação da agressividade na família e escola de Ensino Fundamental. Psico-USF, 14(1), 83-93. Recuperado de http://www.scielo.br/pdf/pusf/v14n1/ aogv14n1.pdf

Lane, K. L., Givner, C. C., \& Pierson, M. R. (2004). Teacher expectations of student behavior: social skills necessary for success in the elementary school classrooms. The Journal of Special Education, 38(2), 104-110. Recuperado de https://pdfs.semanticscholar.org/a1oc/57205f51abb 1afeb4fb6775f72501eb1c316.pdf

Lins, T., Alvarenga, P., Paixão, C., Almeida, E., \& Costa, H. (2012). Problemas externalizantes e agressividade infantil: uma revisão de estudos brasileiros. Arquivos Brasileiros de Psicologia, 64(3), 59-75. Recuperado de http://pepsic.bvsalud.org/scielo. php?script $=$ sci_arttext\&pid=S1809-52672012000300005\&lng $=p t$ \&tlng $=\mathrm{pt}$

Menandro, M. C. S., \& Souza, L. G. S. (2010). O que é ser bom aluno? O que é parar de estudar? Representações sociais de estudantes do Ensino Médio. Revista de Educação Pública, 19(39), 75-94. doi: 10.29286/ rep.v19i39.379

Molina, R. C. M., \& Del Prette, Z. A. P. (2006). Funcionalidade da relação entre habilidades sociais e dificuldades de aprendizagem. Psico-USF, 11(1), 53-63. Recuperado de http://pepsic.bvsalud.org/pdf/psicousf/ v11n1/v11n1a07.pdf 
Pestana, M. H., \& Gageiro, J. N. (2003). Análise de dados para ciências sociais: a complementaridade do SPSS (3a. ed.). Lisboa, Portugal: Silabo.

Rodrigues, M. C., \& Silva, R. L. M. (2012). Avaliação de um programa de promoção da empatia implementado na educação infantil. Estudos $e$ Pesquisas em Psicologia, 12(1), 59-75. Recuperado de http://pepsic. bvsalud.org/pdf/epp/v12n1/v12n1ao4.pdf

Soares, A. B., Naiff, A. M., Fonseca, L. B. da., Cardozo, A., \& Baldez, M. O. (2009). Estudo comparativo de habilidades sociais e variáveis sociodemográficas de professores. Psicologia: Teoria e Prática, 11(1), 35-49. Recuperado de http://pepsic.bvsalud.org/scielo. php?script=sci_arttext\&pid=S1516-36872009000100004 